Stellenbosch Theological Journal 2021, Vol 7, No 2, 1-21

DOI: http://dx.doi.org/10.17570/stj.2021.v7n2.a4

Online ISSN 2226-2385 | Print ISSN 0028-2006

2021 (c) Pieter de Waal Neethling Trust

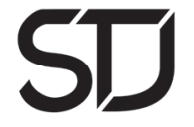

\title{
The phenomenon of divorce and its challenge to the black African communities: A need for pastoral and indigenous African marital therapy
}

\author{
Baloyi Tlharihani \\ University of South Africa \\ baloygt@unisa.ac.za \\ Buffel Olehile \\ University of South Africa \\ buffeoa@unisa.ac.za
}

\begin{abstract}
Divorce is a painful and traumatic experience that disrupts the lives of people. Research has shown that the phenomenon of divorce among black South Africans is escalating on a yearly basis. This is accompanied by emotional, spiritual, and psychological effects which impact on the well-being of people. Furthermore, divorce is understood as a disruption of normal life and it also threatens the stability and sustainability of social institutions. As the article is written from a context of pastoral therapy, it acknowledges the existence of other forms of care beyond the boundaries of the Christian ministry of healing. The indigenous African marital therapy plays a vital role in black African communities in strengthening marital bonds and its longevity. Even though this African model has been disrupted by the wave of industrialisation and urbanisation, the article argues that its methods of healing, counselling and mediatory role are necessary for African people and in response to the collapse of the institution of marriage.
\end{abstract}

Keywords

Divorce; healing; indigenous African Marital Therapy; marriage; pastoral therapy

\section{Introduction}

The article deals with the phenomenon of divorce which is becoming common in contemporary society. This phenomenon is also disrupting normal life of couples, children, families, and social institutions. While 
aware that there is now the civil union (in terms of Civil Union Act No 17 of 2006 as amended) related to same-sex relationships, the article confines itself to marriage in heterosexual and monogamous relationships (in terms of the Marriage Act No 25 of 1961 as amended). The article argues that while pastoral therapy (as non-African based model) has done well in Christian counselling, there is much to be gained and learned from the indigenous African marital therapy. As this play a significant role in black African communities, its incorporation to the therapy models would enrich the therapy for African people. While this indigenous African marital therapy approach is common in most regions of Africa, the approach in this article is located within communities such as the Sotho, Tswana, and Tsonga ethnic groups. This model can go a long way as part of pastoral therapy, a perspective from which this article is written.

\section{Divorce as a painful societal phenomenon of interests to many fields}

According to Ackerman, divorce is a societal phenomenon of interests to most fields, particularly Social Work, Psychology and Sociology (Ackerman 2014:366). It is also of interests to theological disciplines, particularly to Pastoral therapy. Divorce is a painful and traumatic experience that disrupt the lives of all those who are involved in the process. The phenomenon of divorce does not happen in vacuum, but it causes havoc and disruptions in the context of struggles and challenges prevalent in marriage and family dynamics. According to Waruta and Kinoti (2013:102), "The institution of the family in African society, as in most other societies of the world, is founded on marriage." From this context, marriage is defined as a matrimonial "union of a man and a woman ..." for the purpose of procreation and mutual assistance (Hastings 1973:27; cf. Izekwe 2015:24). Although some scholars such as Mbiti (1969:133) and Perez-Lopez (2017:304), argue that without procreation, marriage is incomplete. However, it should be appreciated that children are a gift from the divine God as stated in Psalm (127:3) which says, "Behold, children are a heritage from the Lord. The fruit of the womb is a reward."

Many African people regard marriage as a sign of maturity, normality, and a vital step in maintaining the consistency of the society. According 
to Kalule-Sabiti et al (2007:89), "Like most societies, the institution of marriage has always played a central role in shaping the family in South African society." Many South African societies and other African countries understand marriage as "more than being together" as couple (Kefalas et al 2011:845). It is about two families (with each's extended families) coming together to form one large family. Notwithstanding difference in the traditions, customs, and norms, among the various African groups, marriage was treated as sacred. John Mbiti (1969:133) states that from an African point of view:

... marriage is the focus of existence. It is the point where all members of a given community meet: the departed, the living and those yet to be born. All the dimensions of time meet here and the whole drama of history is repeated, renewed, and revitalized. Marriage is a drama in which everyone becomes an actor or actress and not just a spectator. Therefore, marriage is a duty, a requirement from the corporate society and a rhythm of life in which everyone must participate.

From Mbiti's point of view, most people enter a marriage union without an intention or anticipation of ever getting divorced. This is based on the premise that marriage is "... considered to be a lifelong union" as correctly pointed out by Waruta (2013:105). Inevitably, marriage has certain traditional expectations from the couple, as imposed by extended families and society.

Although initially divorce was rare, it has now been established as an acceptable norm in many societies, including African societies. This does not suggest that divorce was not conceivable in African societies, but it was not a common practice. Waruta (2013) states that some of the grounds which were considered serious for divorce in African societies included among others, “... cruelty, charges of sorcery, incompatibility, quarrelling between co-wives [in a case of polygamous marriage], laziness, adultery and ... childlessness" (2013:105). These were uncommon cases to have and to charge someone to a point of dissolving marriage. The normalisation of divorce is an erosion of significant values which were attached to the institution of marriage. Eldar-Avidan (2009:30), pointed out that, "the role of marriage in coordinating social life has eroded." (cf. Kefalas et 
al 2011:846). In her overview of the phenomenon of divorce, Ackerman argues that although divorce is increasing in South Africa, contrary to popular belief, South Africa does not have the highest divorce rate in the world (Ackerman 2014:366).

According to Stats SA (2018:6-45), divorce rates in South Africa have increased within the period 2009-2018. The 2018 divorce data is based on 25284 completed divorce forms that Stats SA obtained and processed by the end of December 2018 (Stats SA 2018: 6). The Stats SA (2018:37) shows that in 2018, black African couples had the greatest number of divorces in comparison to other population groups throughout the ten-year period (2009 to 2018). It further shows that in 2018, most divorces were filed by the black African population group $11721(46,4 \%)$ followed by the white population group 5780 (22, 9\%), coloured population group 4540 (18, 0\%) and then the Indian/Asian population group 1214 (4, 8\%). The percentage is too high in comparison with the past, notwithstanding the fact that black Africans constitute an overwhelming majority in the South African population.

Marriage and family were significant central institutions in the social process. However, the high statistics continue to demonstrate that these institutions are now weakened. While there are myriad reasons why divorce cases keep rising, the main concern is that the declining institutions mean that more children are left shattered in two worlds (Priest et al 2015; Pauli \& van Dijk 2016; Kudakwashe et al 2018; Mnyango \& Alpaslan 2018). As marriages break down at an alarming rate in South Africa, that obviously affects many people negatively, ranging from individuals, children and other members of extended families. Using the statistics of 2006, De Jong argues that in the cases of approximately 31000 divorces that were recorded that year, they had implications for over 60000 adults and approximately 31000 children affected by divorce that year (De Jong 2010:510). The parties involved experienced emotional and physical distress, which often manifests as inter alia insomnia, depression, weight loss and panic attacks.

This article is written from the perspective of pastoral therapy within the milieu of African people. It proposes the indigenous African marital therapy as vital model to be integrated into the field and practice of pastoral therapy in response to the challenge of divorce in society. The role 
of the council of elders, parents, aunts, and uncles in providing indigenous African martial therapy has lost its powerful impact due to the influx to cities and in industrialisation and urbanisation. This article argues that the council of elders is rich in matters of family affairs, marital life and they are able to provide deeper marital therapy from the perspective of indigenous African people. Mediation has always been central to all dispute resolution mechanisms in Africa, as De Jong correctly acknowledges that "mediation has always been an essential part of African families and society" (2010:527). Therefore, there is a need for pastoral collaboration with this indigenous model of resolving family disputes in order to strengthen marital life and sustenance of family life in the society.

\section{Divorce as a challenge to individual, family, and societal well- being}

The phenomenon of divorce is a painful reality with challenges and effects on many people, ranging from individuals, couples, families, and societies. Divorce destroys the beauty and sanctity of the institution of marriage and what it represents in society. Within the black African communities, marriage was never left up to the individuals but was connected to the entire kinship system. In the kinship system, every person was involved in the process of ensuring that longevity and quality of marriage is maintained (cf. Waruta 2013: 101-119). Furthermore, the kinship system, provided indigenous African marital therapy and every person counted on the model for the sustenance of marriage. Today however, divorce is made and introduced as a social norm, and both longevity and quality of marriage decreases yearly (Stats SA 2018). This erodes the values attached to the institution of marriage and family. Furthermore, the growing stats on divorce have many implications for the future of society and its existence. While we acknowledge that there are many reasons behind the erosion of marriage and the growing cases of divorce, it remains a fact that marriage is a necessary institution in the world. The growing statistics on divorce cases gives a sense that the modern society is incapable of tolerating difference in marriage and thereby seek help.

Not only is divorce a threat to the future of social institutions, but it poses some emotional and psychological challenges on the people who are 
divorcing and those around them. While this is true, it is also presented by some researchers such as Leopold (2016) that men find it difficult to accept the realities of divorce and to share their emotions compared to women. According to Mnyango \& Alpaslan (2018:69), “... men appear to find it more difficult, or even unacceptable, to articulate their deepest feelings, worries, fears, insecurities, emotional pain and grief associated with the losses resulting from divorce." Robards et al (2012:295-299), state that the phenomenon of divorce is associated with the worsening of physical and mental health conditions which are stronger for men than for women. This does not suggest that divorced women do not suffer physical and emotional health, but it states that the harmful effects are more devastating for men. Some of these emotions, happen during the separation stage, where possibilities of fixing the marriage conflicts through martial therapy are possible. However, some African men do not talk about these challenges as they present themselves as less vulnerable and they pretend to be strong as they avoid expressing their feelings and displaying their vulnerabilities that could reduce their sense of self-worth.

According to Mnyango \& Alpslan (2018: 69), "Men are less prone to reach out for help with the pain and stress arising from separation and divorce partly because of the "men-must-be-strong" ethos maintaining that men who seek professional help are "weak, vulnerable and incompetent." This attitude is also observed in some South African societies where it is considered taboo for black men to shed tears especially in public places (Kudakwashe et al 2019). Such men are considered weaklings with their families, cycle of friend and colleagues and within their clans. This culture of "like tigers, men do not cry" or share burdens and challenges with others is problematic in a sense that, it creates elements of anger and bitterness in oneself. The inability of most men to talk openly about their emotional challenges makes the healing process more difficult and impossible. However, this attitude has its roots in the patriarchal mindset according to which crying is regarded as an act reserved for women and therefore symbolises weakness if done by men (Kudakwashe et al 2019: 8).

In the context of some African traditional societies where marriage is regarded as a sign of maturity, a married man feels a sense of belonging to a cycle of what they call "real men" by virtue of marriage (see, De-Gaia 2019:16). In other words, they considered marriage as key to a societal 
recognition and a form of acceptance into adulthood (cf. Pike et al 2018: 1-21). Kudakwashe et al (2019: 8) had this to say,

Divorce, like marriage, is a public event in that it is observed by the respective families, friends, and the network of contacts of the couple. This can cause stress and feelings of humiliation and remorse.

In the process of their interviews with participants, Kudakwashe et al (2018: 8) report that one black South African man felt that, "... he had "failed" the whole family, and he had consequently withdrawn from social interaction." However, this leaves one in a state of vulnerability and emotions, which requires care and counselling from different segments of society in view of facilitating healing.

\section{The divorce crisis theory}

Divorce is an emotional crisis, typically triggered by many events resulting in loss of a spouse (Leopold \& Kalmijn 2016:1717). Divorce is understood as a "complex and multidimensional process that unfolds over many years" (Demo \& Fine 2010: 49; cf. Priest et al 2015:487; Abolhassni et al 2017:33). Divorce is also known as a complicated psychological and social process (Leopold \& Kalmijn 2016:1717). However, it is important to note that each individual going through the process of divorce follows a unique course. Although people experience it differently, divorce involves a process where all members of the family system undergo a painful process of transformation, during which each family member may experience some form of bereavement. Several theories have been based on the idea that divorce is a complex psychological and social process rather than a single event. Divorce is best conceptualized as a "process rather that a discrete life event and have identified stages within that process" (Ferreira 2007:14). For Africans, divorce is one social ill that has befallen the larger part of African people. Society itself abhors divorce, and yet marriages fail on daily basis (Kudakwashe et al 2018: 8). This is worrying especially in the African context, where marriage was appreciated as an essential element signifying the focus of existence. Divorce, therefore, barricades the pulse of African cultural marriage in which everyone must become a participant. It reduces 
the significance of marriage and undermines the institution of marriage in an African context.

Although there are number of factors contributing to the rise of divorce amongst African couples, such factors do not eliminate and diminish the African people's understanding of the power of indigenous African marital therapy. For instance, Hastings (1973) indicates that the spouses' ages at the time of marriage is a possible predictor of divorce; Mbiti (1969) argues that childlessness in African marriage can lead to divorce. Hastings (1973) also stressed the possibility of divorce as the result of laziness and infidelity. However, these are not the only reasons why divorce is establishing itself amongst African couples as a growing phenomenon. Numerous aspects contributing to divorce include lack of communication between spouses, financial hardship, falling out of love, lack of commitment to the marriage, and infidelity, alcoholism, irreconcilable differences.

Both Paul Bohannon (1970) and Reva Wiseman (1975) have developed crisis theory and the process or stations of divorce which have been regarded as the most important theories even today. In terms of the stations of divorce, the process is based on the premise that divorce is a process. Bohannon's Six Stations are as follows: (1) Emotional divorce, which involves the loss of affection, trust, and respect. This is a stage which indicate the deterioration of marriage due to the loss of feelings. (2) Legal divorce, which deals with the court order of the termination of marriage. This is a stage which happens during separation and parties agree to end their marriage. (3) Economic divorce is concerned with the settlement of property. (4) Coparental divorce involves decisions regarding child custody, child support, visitation rights, and the various ongoing responsibilities of the parents. (5) Community divorce involves the decrease of membership and sense of belonging to a shared community of mutual relatives and friends. (6) Psychic divorce follows a period of mourning and refers to one's emotional separation from their former partner.

Bohannon's six stations theory of divorce is useful in describing the multiple issues and processes which are involved in a divorce. While Bohannon talks about six stations of divorce which includes many different domains, Wiseman deals specifically with the internal emotional and psychological dimensions. Although the difficulties experienced are different for every 
individual undergoing the divorce process, some common feelings and experiences can be mentioned. Wiseman's (1975:205-212) model comprising of five overlapping stages are summarised as follows:

- Denial is the stage before the marital problems are consciously acknowledged. During this stage conflictual issues tend to be either ignored or attributed to external causes by the spouses.

- Loss and depression follow once a crisis has set in and the spouses are forced to acknowledge that the marriage has serious problems.

- Anger and ambivalence are experienced during the next stage, when the interactions between spouses may turn vindictive, punitive, or even violent. This is a period of emotional purging, which eventually culminates in the decision to separate.

- Reorientation of lifestyle and identity is the recognition of being a single person once again. This is a time where individuals start to accept the reality of their divorce. The challenge of this stage lies in redefining an identity outside of marriage. It is also a time for considering the nature of potential future relationships.

- Acceptance and integration reflect the final resolution of divorce. In this stage the divorced person has accepted their new identity and lifestyle, has nothing to prove and no need to be defensive and a sense of peace (see Clarke-Stewart \& Brentano 2006:23-24; Everett 1991:1).

Bohannon's theory incorporates many different domains of an individual's life, while Wiseman theory focuses on the internal emotional and psychological dimensions of divorce. These stages are helpful in facilitating the understanding of the theory and stages of divorce in order to provide holistic counselling. According to Mwaura (2013:78),

The human being is not a fragmentation but a complete entity, needing healing for his or her whole being - spiritually, socially, physically, psychologically and in relationship with his/her environment.

It is in view of this that holistic approach to healing is advocated, with appreciation of the combination of pastoral therapy and indigenous African marital therapy. The emphasis here is that, if pastoral therapy is to play a healing role, it must first understand these dimensions in order 
to provide relevant techniques. It is also important that the indigenous African approach to healing, is conceived as more than physical well-being.

\section{Indigenous African marital therapy}

The escalating cases of divorce among black South Africans is worrying (Stats SA 2018). This is based on the fact that the notion of marriage is taken very seriously by African people, and therefore, divorce is a direct threat to the future of society. Most of South African indigenous people have had methods of solving conflicts between a man and a woman in marriage. According to Sodi et al (2010:336) "Traditional marital conflict mediation in Africa has the sole aim of reuniting the couple since divorce is rarely considered as an option to troubled marriages." This provides a foundation for the need to resuscitate and promote the indigenous African methods of counselling and therapy, in view of facilitating restoration of the sanctity of and permanent nature of marriage.

Sodi et al (2010:336) defines marital therapy as,

... any therapeutic intervention technique aimed at assisting troubled marriages and couples to better understand their reciprocal marital interaction and attempt to find ways in which their needs can be mutually satisfied so that the growth and development of each partner can be maximised in the relationship.

The indigenous African marital therapy is understood as part of the broader counselling model; however the indigenous African approach is rich in its holistic approach (Madu et al. 1996). Nwoye (2000:348) states,

African marriage therapy follows the guide of its cultural heritage and takes the character of a mediatorial session. This involves the presence of a mediating team of elders as the jury, with the couples in conflict being litigants.

The prime purpose is helping build and strengthen the marital bond of the couple in question. This is a process involving many procedures and council of elders as opposed to the western therapy. According to Sodi et al (2010:336), 
In indigenous marital counselling the respect and the authority of parents, including the counsel of uncles, aunts, and grandparents, is of paramount importance. In this context, marriage counselling helps couples to learn to deal more effectively with their problems.

These are elders who have enquired vast knowledge of philosophy of life and are often found in every society. Like many values and things lost, traditional structures are no longer equipped to play traditional roles due to circumstances and conditions that are changing. The lost values and principles must be rediscovered in some ways and this may even involve reequipping of the elders so that they may play a meaningful role in playing mediatory roles. Furthermore, they are viewed as trustworthy mediators who have accumulated wisdom over the years of life.

The indigenous African value system preserves certain qualities that western approach to therapy is not able to provide in an institution of marriage (see Nwoye 2000: 347-359). The system is not characterised by individualism but by communal approach which includes a rediscovery of Ubuntu as a philosophy and a way of life. This is similar to what Nwoye (2000 348) described as "... mediating team of elders as the jury, with the couples in conflict being litigants." The purpose here is to have the marriage strengthened to avoid divorces from occurring. Although "the growing freedom of young people ..." and the “... urban life as a result of industrialisation...” as Waruta (2013: 113) and Magezi (2018:5) correctly points out, these have contributed to the weakening of the African value system. In addition, this does not take away the fact that this communal system is vital and necessary for African people. In an environment where there are breakdown of kinship and people cannot find support from their relatives, the entire indigenous African support structure is made to lose its power and authority. Waruta (2013:115) reminds us "African people should never ignore the role of traditional African values even in the context of contemporary changes."

Although the Afrocentric approach to marital therapy differs from the Eurocentric approach, each context aims towards providing therapy best in their own contexts. While the Eurocentric approach is limited to certain people, the Afrocentric incorporates sociological dimensions that are not there in the Eurocentric. The African societal marital therapy includes 
among others, the spiritual, physical, mental, social, family unit with its extended members, the holistic expectations and behaviour in marriage. It follows the guide of its cultural heritage, values and takes the character of a communal session where most elders form part of the counselling team. According to Mtshali (2017:23), "this process includes advising, guiding and condemning any behaviour that could anger ancestral spirits." Within a black African context, marriage does not exclude the ancestors of the families whether their spirits are invoked or not. Any therapeutic process is connected to spirituality.

Within this, exists an understanding that dishonouring such an institution by resorting to divorce, brings shame to the family, community, and ancestors. Though we need to note and appreciate that there are cases where divorce may be necessary and may be a lessor of the two evils, vis-avis the couple destroying each other and in some cases one party killing the other. The values systems given by council of elders are to be implemented for the preservation of marriage. The indigenous African marital therapy is based on the understanding that a child belongs to the community and that the process of educating him/her continues until death (cf. Chisale 2018:7). Furthermore, such responsibilities are not left completely in the hands of the parents, but to the elders of the family and community.

Tom and Chipenda (2019:154) correctly points out that “... the family in the traditional African context is understood in relation to the whole community." In this way, caring for one another is equally understood as the responsibility of the community. Even in the context of searching for “... justice and [when] conflicts emerge ... restoration of sound relationship is prioritised” (Tom \& Chipenda 2019:154). Kitson (1981:25) states, "Social support has been defined as formal and informal contacts with individuals and groups that provide emotional or material resources that may aid a person in adjusting to a crisis such as separation or divorce." Resuscitating this system, would also mean making use of the indigenous system even in the context of industrialisation. The indigenous African values that helps even in marital crisis, should not be made less important by the wave of Industrialisation. In other words, there should be no gap that exists between the rural and city lifestyle or industrialisation. 
A balance is needed in such a way that those who are residing in the urban environment, should still connect with the elders in the rural areas for continuous therapy. In other words, this therapy should not be once off sessions, but a regular exercise in view of contributing to a sound society with value systems. One of the ways in which this could be done, is to create Imbizo (the gathering) in which the elders would have an opportunity to engage with the couple. The African indigenous way of life has to be made more important for black Africans to understand their African roots and heritage. This would eliminate what Magezi (2016:83) describes as "living life in the between," that is, living in two worlds without belonging to either. Magezi argues that the double life would mean living a "traditional African person who upholds traditional values, ethics and customs of relationality and communality. On the other hand, one has to live a life that suits urban and Western life practices" (Magezi 2018:3). The main idea in this is to try to help married couple sustain their marital union to death and this would work as a strategy to avoid possibilities of separation and divorce where possible.

In a context where divorce has happened, this indigenous system should still be able to care and provide resilient methods for individuals in view of enabling couples to bounce back after adversity. This indigenous system should also eliminate factors, which may lead to barrier of healing. Inasmuch as we appreciate the goodness of the indigenous African marital system, we also need to acknowledge the possibility of negative aspects of African culture such as patriarchal dimensions of culture that support and sustain the dominance of males in the society. This speaks to the context where separation or divorce has occurred, a man is expected to be strong and not shed any tears. This is a perpetuation of a patriarchal mindset, which promotes barriers for healing. This patriarchal mind set which associate crying with women, does strengthens and promote the cultural barrier in which men becomes 'walking graves.' We use the concept of 'walking graves' deliberately to describe the danger of many unresolved issues, which also have the potential to become catastrophic in their lives and that of others. If indigenous African marital therapy is to be resuscitated, this patriarchal mindset has to die in order for their healing process to be genuine and complete. 


\section{Pastoral therapy and its shortcomings}

Pastoral therapy views human condition from a spiritual perspective and that holistic healing is necessary to take place in totality. This is based on the fact that "... human crises have a spiritual dimension and that they cannot be fully overcome until the spiritual yearning of the human being have been met" (Waruta \& Kinoti 2013:6). In its approach, it does not incorporate the African communal dimensions which allow therapy to be offered broadly. it fails to recognise that Christianity is not substitute of the values of African people, but a form of connection with God the creator. Furthermore, it fails to recognise that therapy is not only about educational training where a young pastor can work alone with the couple. It is rather an exercise that requires life experience from the circle of elders in the community despite their outward appearance and religious backgrounds.

However, the Christian ministry of healing has not succeeded in this approach and strengthening families through marriage, especially in the context black African people. There are numerous reasons why the Christian ministry has not fully succeeded in terms of pastoral counselling. The Christian healing approach is based on the fact that this ministry of healing fails to reflect African elements in it for its relevance to the indigenous people. Part of this problem was created by some missionaries who did not appreciate the healing art and models of the indigenous African people.

It remains a fact that some missionaries often held negative attitudes towards indigenous African traditional value systems and replaced those with the Eurocentric approach (Shorter 1973; cf. Maluleke 2020:24). As a result, when missionaries established Christian marital therapy, they generally did not consider integrating indigenous African traditional marital therapy as part of the resources for premarital counselling (see Maluleke 2020;19-36). The interest was not much in the African systems, but on introducing the Eurocentric systems and ways of life in dealing with human challenges. This shift, forced African people out of their ways of life and embraced the new way of thinking, seeing life and understanding things. According to Waruta (2013:108) the refusal of most missionaries to study and appreciate the positive aspects of the indigenous African custom and ways of life is the basis on which African people have challenges in their communities. The people among whom Christianity was spread had 
to cast away their indigenous clothing, their customs, and their beliefs which were all described as pagan and barbaric (Biko 1978:60). There was no willingness on the side of the missionaries to observe and appreciate part of the values of that were positive to society.

Nonetheless, the church in its pastoral ministry of healing and counselling, is in a good position to create a family counselling model based on an understanding of the African culture (Kapolo 2001:130). The main purpose here is to integrate the indigenous African marital therapy care with Christian pastoral counselling in order to enrich the caring model in society. The indigenous caring model is not an enemy of the Christian church as was alleged by some missionaries, but a complementarity in enhancing the quality of life. This is vital for an African church that cares for African people in their indigenous African societies. Magezi (2007:658) reminds us "... that a pastoral counsellor in Africa should be aware of the crucial role played by the African worldview in order to have meaningful diagnosis."

Patton's (1993: 15) work is an appreciation that communal contextual is vital and necessary especially in the African context. This approach highlights the task of pastoral therapy as a mission of the whole Christian community which focuses on the holistic or contextual dimensions of human beings. This also keeps in mind the need for relevancy especially, in the context of those in need of help. Magezi (2007:658) argues,

Pastoral counselling should take people's contexts seriously; and in order for pastoral counselling and diagnosis in Africa to be effective, knowledge of the African worldview is crucial for interpreting the conversation.

This means that pastoral ministry should touch all the aspects of human existence and be able to provide care and healing. It should be noted that, caring and counselling are not functions that are left in the hands of ministers and other professional counsellors, but these are functions of the whole community. To limit these functions solely to the church and professional counselling, would be to ignore the fact that, humanity exist beyond the borders of the church and professional office spaces. 
In some cases, it failed to include other important issues related to marriage, such as marital relationships between the spouses and matters related to family boundaries. Pastoral therapist today needs to be more cognizant of these matters and incorporate them into their teachings. There is need for inclusion of the indigenous African therapy into the ministry of pastoral work in order to have a holistic approach in to martial counselling.

\section{Conclusion}

Pastoral therapy remains an important aspect of the Christian ministry. However, for this pastoral therapy to be effective and relevant within Christian ministry in the context of African people, it has to appreciate the indigenous African marital therapy as vital tools in the field of counselling. A church which exists in African societies, should be relevant for the people in which it exists. The need to include indigenous African therapy into the ministry of pastoral therapy will enrich the entire field of counselling in the Christian ministry. This work should provide a place for pastoral therapists to serve as a marriage counsellor to educate young people about family boundaries and to work with the council of elders where possible.

\section{References}

Abolhassni, A., Pourebrahim, T., \& Khoshkonesh, A., 2017. The Investigation and Comparison of Experience of Divorce in Divorced Men and Women (Meanings, Contexts, Outcomes, and Adjustment after Divorce). International Journal of Social Science Studies 5(12):3243.

Ackerman, L. 2014. Divorce in South Africa: An Overview. In Social Work/Maatskaplike Werk 40(4). Doi: 10.15270/40-4-321. [Online]. Available: https://www.researchgate.net/publication/314741322_ DIVORCE_IN_SOUTH_AFRICA_AN_OVERVIEW [Accessed:06-02-2021].

Biko, S. 1978 [2017]. I write what I like. Johannesburg, SA: Macmillan. Bohannon, P. 1970. The six stations of divorce. In Paul Bohannon (ed). Divorce \& after. Doubleday, New York. 
Civil Union Act N) 17 of 2006. Pretoria: Government Gazette, Republic of South Africa. [Online]. Available: https://www.gov.za/sites/default/ files/gcis_document/201409/a17-061.pdf [Accessed: 06-03-2021].

Chisale, S.S. 2018. Disabled motherhood in an African community: Towards an African women theology of disability. In die Skriflig 52(1):1-9.

Clarke-Stewart, K.A. \& Brentano, B. 2006. Divorce: Causes \& consequences. Library of congress, U.S.A.

De-Gaia, S. 2019. Encyclopaedia of Women in world Religions: Faith and Culture across History. California: ABC-LLC.

De Jong, L. 2010. A pragmatic look at mediation as an alternative to divorce litigation. In Tydskrif vir die Suid Afrikaanse Reg. January 2010:515-533. [Online]. Available: http://www.researchgate.net/ publication/289112377 [Accessed: 05-03-2021].

Demo, D.H. \& Fine, MA. 2010. Beyond the Average Divorce. Washington DC: SAGE publications.

Eldar-Avidan, D., Muhammad, M.H. \& Greenbaum, C.W. 2009. Divorce is a part of my lifeResilience, Survival and Vulnerability: Young Adult's perception of the implication of parental divorce. Journal of Marital and Family Therapy 35(1):30-46.

Everett, C.A. (Ed.) 1991. Marital instability and divorce outcomes: Issues for therapists and educators. Binghamton, NY: Haworth Press.

Ferreira Da Costa, T.M. 2007. Divorce as a bifurcation: Redefining a nuclear system. Masters Dissertation in Psychology. Pretoria: Unisa.

Hastings, A. 1973. Christian Marriage in Africa. London: SPCK.

Izekwe, A.C., 2015. The Future of Christian Marriage among the Igbo visá-vis Childlessness. A Canonical cum pastoral study of canon 1055 par.1. Berlin: Logos Verlag.

Kalule-Sabiti, I., Palamuleni, M., Makiwane, M., \& Amoateng, A,Y., 2007. Family Formation and Dissolution Patterns. In A.Y. Amoateng \& T.B. Heaton. Families and Households in Post-apartheid South Africa: Socio-demographic Perspectives. Cape Town: HSRC Press. 89-112. 
Kapolo, M. 2001. Premarital pastoral care and counseling: Quest for an African model. Word \& World 21(2):129-134.

Kefalas, M., Carr, P., Napolitano, L., \& Furstenberg, F F. 2011, Marriage is more than being together: The meaning of marriage for young adults. Journal of Family Issues 32(7):845-75.

Kitson, G.C. \& Raschke, H.J. 1981. Divorce research: What we know: what we need to know. Journal of Divorce 4(3):1-37.

Kudakwashe, C., Muchena, G,H., \& Stroud, L.A. 2019. “Men don't cry”: An Interpretative Phenomenological Analysis of Black South African Men's Experience of Divorce. Indo-Pacific Journal of Phenomenology 18(2):29-40.

Leopold, T. \& Kalmijn, M. 2016. Is divorce more painful when couples have children? Evidence from long-term panel data on multiple domains of well-being. Demography 53(6):1717-1742.

Madu, S.N., Baguma, P.K. \& Pritz, A. (Eds.) 1996). Psychotherapy in Africa: First investigations. Vienna: World Council for Psychotherapy.

Magezi, V. 2007. Pastoral counselling: Towards a diagnostic and interpretational approach in Africa. Skriflig 41(4):655-672.

Magezi, V. 2016, Pastoral care within globalisation care at the inbetween: The dynamics of pastoral care and counselling for meaning and Coping in a global context. In U. Elsdörfer \& T.K. Ito (eds.). Compassion for one another in the Global village: Social and cultural approaches to care and counselling. Wien: LIT VERLAG.

Magezi, V. 2018. Changing family patterns from rural to urban and living in the in-between: A public practical theological responsive ministerial approach in Africa. HTS Teologiese Studies/Theological Studies 74(1):1-8.

Maluleke, T.S. 2020. Racism en route, an African Perspective. Ecumenical Review. World Council of Churches, 72(1):19-36.

Marriage Act NO 25 of 1961. Pretoria: Republic of South Africa [Online]. Available: https://www.gov.za/sites/default/files/gcis_ document/201505/act-25-1961.pdf [Accessed:06-03-2021]. 
Mbiti, J.S. 1969. African Religion and Philosophy. London: Heinemann

Mnyango, R P. \& Alpaslan, N. 2018. Let's talk about divorce - Men's experiences, challenges, coping resources and suggestions for social worker support. Social Work/Maatskaplike Werk 54(1):69-90.

Mwaura, P N. 2013, Healing as a Pastoral Concern. In D.W. Waruta \& H.W Kinoti. Pastoral acre in African Christianity: Challenging essays in pastoral theology. Nairobi: Acton Publishers. 72-100

Mtshali, P.S. 2017. Exploring the meaning attached to seeking marital therapy among married African males in the Durban area.

Unpublished Master of Art, Department of Psychology, University of Zululand.

Nwoye, A. 2000. Building on the indigenous: theory and method of marriage therapy in contemporary Eastern and Western Africa. Journal of Family Therapy 22(4):347-359.

Nwoye, A. 2006. Theory and Method of Marriage Therapy in Contemporary Africa. Contemporary Family Therapy 28(4):437-457.

Patton, J. (1993). Pastoral Care in Context - An Introduction to Pastoral Care. Louisville: Westminster/John Knox Press.

Pauli, J. \& van Dijk, R. 2016. Marriage as an end or the end of marriage? Change and Continuity in Southern African marriages. Anthropology Southern Africa 39(4):257-266.

Perez-Lopez, A. 2017. Procreation and the Spousal Meaning of the Body: A Thomistic Argument Grounded in Vatican II. Oregon: Wipf \& Stock Publishers.

Pike, I., Mojola, S,A. \& Karibu, C.W. 2018. Making Sense of Marriage: Gender and theTransition to Adulthood in Nairobi, Kenya, Journal of Marriage Family 80(5):1-21.

Priest, J B., Salts, C. \& Smith, T. 2015. Special topic in family therapy: mental illness, physical illness, substance abuse, family violence and divorce. In J.L. Wetchler \& L.L. Hecker. An Introduction to Marriage and family therapy. London: Routledge. 468-504. 
Robards, J., Evandrou, M., Falkingham, J. \& Vlachantoni, A. 2012. Marital Status, Health and Mortality. Maturitas 73(4):295-299.

Shorter, A. 1973. African Culture and the Christian Church. London: Geoffrey Chapman.

Statistics South Africa, 2018. Marriages and Divorce. Pretoria: Statistics South Africa [Online]. Available: https://www.divorcelaws.co.za/ uploads/1/2/1/6/12166127/divorce_stats_2018.pdf [Accessed: 06-032021].

Tom, T. \& Chipenda, c. 2019. Grassroots Mechanisms for Justice, Peace-building, and Social Cohesion in Zimbabwe's "New" Farm Communities". In E. Benyera. Indigenous, Traditional, and Nonstate transitional Justice in Southern Africa Zimbabwe and Namibia. London: Lexington Books: 141-163.

Waruta, D.W. 2013. Marriage and Family in contemporary African society: Challenges in pastoral counselling. In D.W. Waruta \& H.W. Kinoti. Pastoral acre in African Christianity: Challenging essays in pastoral theology. Nairobi: Acton Publishers. 101-119.

Wiseman, R.S. 1975. Crisis theory and the process of divorce. Social Casework 56(4):205-212. 